\title{
Arquivos do performer e Arquivos de performance: o relato de uma experiência da constituição de um processo reflexivo
}

\author{
Daniel Vieira (ISEI/ASCARTE) \\ Any Raquel de Carvalho (UFRGS)
}

\begin{abstract}
Resumo: A partir da ideia de ruptura paradigmática imperativa para a pesquisa em Práticas Interpretativas, o artigo sugere uma possível problematização do sujeito a partir do princípio do cuidado de si como apresentado por Foucault (2010) e convertidos para a música por Vieira (2012). Tal pressuposto metodológico procura demonstrar como a integração entre sujeito e objeto no processo de performance conduz fértil fonte de objetos teóricos para a própria prática artística e prática de pesquisa. O princípio do cuidado de si apresenta um conjunto de procedimentos que atuam progressivamente sobre o indivíduo em termos de aprimoramento da alma do sujeito, sublinhando sua espontaneidade tal qual o sentido da subjetivação. Assim, a manutenção de arquivos de registros das atividades envolvidas na prática musical que representam o retorno à humanidade e a individualidade presente no ato da performance - arquivos do performer e arquivos de performance servem de suporte para a reflexão que conduz a constituição do sujeito subjetivado. Tal constituição denota uma ideia de apropriação de construções e elaborações sobre o discurso musical a partir da alteridade tornando-se parte da própria essência do performer.
\end{abstract}

Palavras-chave: pesquisa em práticas interpretativas, cuidado de si, constituição de si, processo de performance, filosofia da performance musical.

\section{ARCHIVES OF THE PERFORMER AND ARCHIVES OF PERFORMANCE: A REPORT OF AN EXPERIENCE OF THE CONSTITUTION OF A REFLECTIVE PROCESS}

Abstract: From the idea of paradigmatic rupture, imperative for research in Musical Performance, this paper suggests a possible questioning of the subject from the principle of the self-care as outlined by Foucault (2010) and converted to the musical scene by Vieira (2012). This methodological assumption explains how the integration between subject and object in the process of performance leads fertile source of theoretical objects to one's own artistic practice and research practice. The principle of self-care has a set of procedures that act gradually over the individual in terms of improvement of the soul of the subject, emphasizing spontaneity as well as the sense of subjectivity. Thus, maintaining file records of the activities involved in musical practice that represent a return to humanity and individuality present in the act of performance - archives of the performer and files and archives of the performance - serve as support for reflection that leads to the formation of the subjected subject. This constitution denotes an idea of the appropriation of construction and elaborations of the musical discourse of the otherness from becoming part of the very essence of the performer.

Keywords: research in musical performance, self-care, constitution of self, process of performance, philosophy of musical performance. 
A pesquisa em Práticas Interpretativas no Brasil, em geral, tem vivido uma época de transição e vislumbrado um novo paradigma que, como Boaventura de Souza Santos (2002) sugere para o campo das humanidades, assinala para uma ciência pós-moderna correspondendo à necessidade de pensamento emergente. Essa nova percepção implica em clara modificação do relacionamento entre o científico e a incorporação das artes na universidade. Tal paradigma corrobora com o fato que acompanha toda e qualquer pesquisa nessa área: a produção de conhecimento que, de alguma maneira, auxiliará o performer em sua práxis, seja ela tocar ou ensinar alguém a tocar (Barrenechea, 2003; Aquino, 2003).

Em acréscimo, observamos que tal transição paradigmática procura definir objetivos que necessitam ser submetidos a uma crítica sistemática suspeita de imparcialidade e conquista real de espaço dentro da ciência do conhecimento. Se o todo e a parte são ilusões mecânicas, como infere Santos (2002), acreditamos que, o inter-relacionamento entre a práxis profissional artística e a práxis de pesquisa do performer pesquisador cumpre-se 'desconstruindo' os diferentes objetos teóricos e as diferentes representações que são subentendidas. Essa desconstrução tende a tornar compreensível a razão acerca da utilização e sugestão de tais objetos, de modo que a aplicação da ciência contra a própria ciência, como um exercício epistemológico, leva a dizer o que se sabe de si, além de considerar ignorada toda a posse de saber da sociedade (Santos, 2002). Dessa maneira, em se tratando da pesquisa em Práticas Interpretativas, o processo reflexivo-crítico, quer de performance como de pesquisa, estaria cada vez mais vinculado à criação de seus próprios objetos teóricos, potencial problematização do próprio sujeito da performance e, em suma, a construção de uma subjetividade decorrente do produto objetivado cientificamente.

O presente relato procura demonstrar como a integração entre sujeito e objeto no processo de performance conduz àquela problematização referida, de maneira que sua iminente subjetivação torna-se fértil fonte de objetos teóricos para a própria prática artística e prática de pesquisa. A experiência aqui narrada teve como ponto de partida e alicerce a própria prática musical. Toda a suposta 
incorporação tácita, que the é natural, foi tratada de modo espontâneo, de maneira a integrar a constituição pretendida. Além disso, a fixação de uma obra no repertório e condicionamento estético causal para as escolhas interpretativas foram admitidos como base de escopo do processo de performance pretendido.

Essas considerações favoreceram a vinculação e incorporação do paradigma pós-moderno. Como em consequência, o princípio do cuidado de si, desenvolvido por Foucault no curso do Collège de France intitulado "A Hermenêutica do Sujeito" (Foucault, 2010) é referido, neste relato, como teoria fundamental para o escopo metodológico. O cuidado de si, entretanto, já denota uma certa 'tecnologia' para a atividade de subjetivação-objetivação pretendida, gerando, da própria observação do sujeito como agente e objeto de seu próprio conhecimento, a sua problematização que favorece a valorização da práxis profissional musical do próprio pesquisador.

O princípio do cuidado de si, como desenvolvido por Foucault (2010) e vinculado à música por Vieira (2012), apresenta um conjunto de procedimentos que atuam progressivamente sobre o eu. Pensar nesses procedimentos como possibilidade de estetização sublinha a espontaneidade que atua tal qual o sentido da subjetivação. Dessa subjetivação da alma do sujeito conduz-se a um movimento de ascese. ${ }^{1}$ Entende-se subjetivação da alma como uma possibilidade de realização física de um corpo de reflexões cabíveis que levam à consciência de si, como constituição de si, tornando aquele sujeito como indivíduo de si. Assim, a ascese caracteriza-se pela possibilidade de aprimoramento da alma que visa um domínio sobre si para depois ampliar-se sobre os outros dentro do grupo a que se pertence. Essa constituição de si não ocorre sem a participação do outro, tampouco acontece sem o conhecimento consciente da sua própria origem valorizado como a priori, sendo fundamental a apropriação dessa condição de forma que essa compleição é dada com a possibilidade de exercícios de uma escrita/escuta e leitura de si, a partir do outro desdobrado sobre si para consigo.

${ }^{1}$ O Dicionário de Filosofia Abbagnano define ascese propriamente como um exercício e informa que, na origem, tal expressão indicou o treinamento dos atletas e as suas regras de vida. Com os pitagóricos, os cínicos e os estóicos, a palavra começou a ser aplicada à vida moral na medida em que a realização da virtude implica na limitação dos desejos e renúncia, em busca pela mortificação da carne e uma purgação do corpo (Abbagnano, 1998, p. 82). 
Para levar a efeito essa prática, uma gama de ações tornou-se necessária: a manutenção de arquivos com registros das atividades envolvidas na prática musical da obra selecionada pelo próprio performer - arquivos de performance representando um lugar de retorno à humanidade e a individualidade presente no ato performado, além da possibilidade de geração de reflexão: arquivos de si que serviam como fonte de estudo, constituição e reflexão de si para o próprio performer. Posteriormente, tais arquivos foram submetidos pelo performer a um grupo de músicos (pianistas) a fim de receber uma apreciação sobre o ato apresentado. Tal feedback/feedforward foi recebido e concedido por meio de cartas (correspondências). Estas, que em sua origem, mostram-se tanto a si quanto ao outro, assumem um caráter reflexivo, simplesmente pela possibilidade garantida em seu ato de escrita e, mais uma vez de retorno à humanidade que a realiza. Esse conjunto de ações interativas foi admitido como arquivos do performer, pois continham informações específicas, do outro sobre si, acerca das performances incluídas, de maneira a compor exercícios de leitura/audição e escrita de sua própria constituição e ascese. Assim, as duas categorias de arquivos mencionadas fazem parte e agem sobre a própria concepção do performer, servindo, de fato, como fatos apriorísticos condicionadores de possível reflexão acerca do ato vivenciado.

Se o alicerce paradigmático para a efetivação dessa pesquisa foi embasado no pensamento pós-moderno e, mesmo que o seu relacionamento, nessa linha pós-moderna, seja realizado por meio da linguagem de interação entre os alteres envolvidos, a constituição é empírica, isto é, um movimento de ascese é proveniente desse inter-relacionamento, pois a humanidade, por sua natureza, é prática, e essa prática, em termos de narrativa, sempre deve ser vivenciada e relatada.

Assim, passamos a relatar uma experiência da busca por um movimento de constituição desse eu envolvido num processo de performance. Quando mencionamos arquivos, esses objetos constituem possibilidade de memória, nesse caso, memórias das ações empreendidas no aprendizado, aprimoramento (fixação 
de obra no repertório) e apresentação em público de uma determinada obra. Neste relato, a obra selecionada foi $A$ Prole do Bebê no. 2 de Heitor Villa-Lobos. ${ }^{2}$

\section{Os arquivos de performance do performer: fatos a priori}

Nessa etapa pretendemos comentar a respeito dos registros vinculados ao processo de performance e de pesquisa na prática musical de um dos autores deste trabalho como performer de A Prole do Bebê no. 2 de Villa-Lobos. Em sua atividade como intérprete, o performer apresentou essa série de peças pela primeira vez em setembro 2008 e, desde então, até a última performance considerada para este escrito (início de 2012) no intuito de aprimorar sua execução dessas peças e, para a sua constituição como intérprete, realizou apresentações esporádicas de toda ou de partes específicas dessa Prole.

Essas performances foram gravadas com a finalidade de observação/audição posterior, a fim de compor um corpo de fatos - arquivos de performance para o performer - que conduzissem à possibilidade de pesquisa acadêmica a partir do próprio ato empírico da performance. A propósito das gravações, Philip (2004) informa que

Os primeiros músicos que ouviram suas próprias gravações, nos primeiros anos do século XX, frequentemente surpreendiam-se com o que ouviam. Subitamente, tornavam-se conscientes das imprecisões e maneirismo de que não haviam suspeitado (Philip, 2004, p. 25).

\footnotetext{
${ }^{2}$ A Prole do Bebê no. 2 de Villa-Lobos é um ciclo de nove peças em que, a princípio, adentra-se ao universo infantil, seu subtítulo é "Os Bichinhos". Esse ciclo pode ser considerado como uma obra que requer do seu intérprete condições de grande virtuosidade (Mariz, 1989). Souza Lima (1976) menciona que a série poderia ser chamada de estudos transcendentais e que nesse grupo de peças pode ser notado um amadurecimento de Villa-Lobos como compositor, ou ainda um compositor "mais consciente, mais vivido, realizando concepções mais sérias, mais objetivas" (Souza Lima, 1976, p. 44). Bruno Kiefer (1986), em acréscimo, afirma que essa série "constitui uma das obras definitivas de Villa-Lobos" (Kiefer, 1986, p. 52). Tarasti (1995) indica que a série retrata o entusiasmo da atmosfera internacional parisiense da época, alguns pontos comuns com a música de Prokofiev e algumas passagens em que a textura se aproxima a das páginas mais complexas de Szymanowski.
} 
Visto a possibilidade de ampliar a gama de consciência a que a audição de gravações de performances próprias pode levar, o efeito mais óbvio da valorização da escuta de gravações realizadas pelo próprio músico torna-o músico mais autocrítico. Precisão e clareza tornaram-se elementos da prática habitual quer nas salas de concerto quanto nos estúdios de gravação, resultando na preocupação com a perfeição técnica por parte desses músicos.

O advento das gravações leva o músico a aprender, ou pelo menos a se interessar e a ouvir o que os outros ouvem. "Se você ouvir sua própria performance, e não gostar do que ouve, você então começa a ajustá-la para algo que soe mais como o que você pensou que estava fazendo" (Philip, 2004, idem). De fato, Philip (2004) indica que já no final do século XX os músicos têm se acostumado a ouvir seus registros e analisar o que ouvem e uma vez que o músico teve a oportunidade de ouvir suas gravações, ele já não volta a um possível estado de inocência com relação ao seu próprio som e ideias articuladas e ouvidas.

O aprendizado com a gravação [o ato de gravar] é algo que muitos grandes músicos reconhecem, mesmo aqueles que não apreciam particularmente a experiência. Mas o resultado aprendido com esse feedback não é apenas mais para a gravação, mas também na performance de concerto [...]. Ao longo do tempo, os hábitos adquiridos durante uma gravação tornaram-se parte da cultura geral de performance, seja em estúdio ou em público. A mais óbvia consequência disso foi um aumento gradual dos padrões de precisão e confiabilidade. Mas a influência da experiência da gravação tem um efeito mais amplo, incentivando mudanças de estilo e técnica, em todos os níveis da criação musical (Philip, 2004, p. 62).

Com isso, aderimos a um estudo relatado por Ryan Daniel (2001) de uma experiência com alunos direcionada à autoavaliação para a performance a partir de gravações audiovisuais. Uma das suas conclusões informa que

embora não substituam os comentários de um professor ou mentor, esse procedimento [de avaliar sua própria performance por meio de uma gravação] potencialmente conduz a um maior grau de independência do estudante na avaliação das suas performances (Daniel, 2001, p. 225). 
A proposta de Daniel (2001), que abarca a escritura de relatórios para cada uma das seções de autoavaliação, também aponta para a percepção de como esses relatórios, que contém informações autocríticas, não são apenas uma base excelente para professores e alunos no pertinente à própria performance, mas proporcionam aos alunos um registro do seu progresso ao longo do tempo. 0 autor sugere que essa prática, além de benéfica para a própria performance, conduz a um exercício de autorreflexão que colabora para o desenvolvimento de habilidades críticas fundamentais para a instrução pedagógica.

Indubitavelmente, para nós a atividade de gravação de performances a título de estudo e autoavaliação representa o instrumento para um poderoso exercício de reflexão sobre si e feedback/feedforward. Acreditamos, de fato, que essa atividade realizada converge para a independência real do músico instrumentista. As informações conhecidas a partir da literatura em geral sobre história das gravações e de seus processos, assim como os experimentos realizados que mencionam a utilização de gravações, apontam para a valorização e incorporação desse recurso na prática de performance. Além disso, essa tarefa é rica em possibilidades reflexivas a partir do exercício da gravação.

Visto que a gravação seria o registro de um ato passado e vivenciado pelo performer, na proposição metodológica da tarefa inserida como escopo deste trabalho, constituiria uma verdade experienciada. Comporia, dessa maneira, uma sequência de fatos apriorísticos que foram empiricamente conhecidos. Ao tomar registros gravados como fatos a priori, o posicionamento filosófico pode os conceber quer do ponto de vista epistemológico, assim como do ponto de vista metafísico. Contudo, numa acepção foucaultiana "trata-se definitivamente da regularidade que torna historicamente possível os enunciados" (Castro, 2009, p. 25). Como estavam no passado, preconizavam um resultado a posteriori que, hoje, torna-se a priori, no sentido de constituir a verdade presente: já os foram tocados, vivenciados e experienciados. Hoje são conhecidos a partir da formatividade que se exerce sobre eles. ${ }^{3}$

${ }^{3}$ Relativo à estética da formatividade de Luigi Pareyson (1997). A esse respeito, Abdo (2000) comenta: Não se trata [...] de uma concepção formalista. No ato da criação, o artista exercita preponderantemente a sua intencionalidade formativa, ou seja, a sua "formatividade", mas isto não ocorre de modo isolado. Ao contrário, toda a sua vida 
Pensar a gravação como um ato apriorístico nos conduziu à ideia de como esse fazer a priori é capaz de gerar influência, mesmo naquele que a realiza, e assim criar uma tradição. Molina (2006) menciona que "os referenciais de uma performance são [...] performáticos, isto é, [apenas] a própria tradição das performances oferecem critérios para avaliar uma performance" (Molina, 2006, p. 23). Assim, os arquivos de performance não poderiam resgatar suas referências a partir do próprio fazer performático? Evidentemente que o mundo entorno dessas performances jamais poderia ser deixado de lado. A observação desses momentos a priori não poderia influir no performer por novas atitudes de performance? Isso não formaria para si a sua tradição? Molina (2006) ainda postula que

O talento individual reconstrói a tradição através de sua própria obra. Essa reconstrução, no entanto, é impessoal, já que a 'a consciência poética se desenvolve na mesma medida em que se sacrifica e se extingue a personalidade' (Molina, 2006, p. 27).

A tradição, dessa maneira, mesmo que individual, como contextualizada, nunca é a única geradora de si. O outro tem o poder sobre ela, principalmente quando se retorna a si, após desdobramentos de si sobre si.

Foram resgatadas, para esse trabalho de reflexão, quatro momentos de performance $^{4}$ que serviram de a priori para a constituição de uma quinta performance. Essas performances foram submetidas à apreciação de três pianistas, com formação pós-graduada, a fim de receber feedbacks/feedforwards e

espiritual (que é indivisível) contribui para o êxito dessa "formação". Assim sendo, em seu "modo de formar", ou seja, em seu "estilo" (que é, naturalmente, ao mesmo tempo pessoal e histórico), concretiza-se toda a sua vontade expressiva e comunicativa; e esta introduz-se na obra já sob a forma de arte, ou seja, como estilo, valor e organicidade (Abdo, 2000, p. 19 - aspas e destaque da autora).

${ }^{4}$ A primeira performance separada é a do primeiro recital de doutorado do (primeiro) autor, em setembro de 2008, no Auditório Tasso Correa do Instituto de Artes da UFRGS. A segunda foi em janeiro de 2010, realizada na Sala Armando Albuquerque do PPGMUS da UFRGS. A terceira performance foi realizada também no Auditório do Instituto de Artes da UFRGS em agosto de 2011. A quarta performance/gravação foi realizada em no Auditório da Secretaria de Cultura da cidade de Uberlândia em ḾG, no final do mês de agosto de 2011. A quinta performance foi realizada em 12/03/2012. As gravações dessas performances encontram-se alocadas no seguinte link: http://www.4shared.com/rar/yNgF01l/Gravaes_de_O_Boisinho_de_Chumb.html 
direcionar o trabalho para uma atitude de reflexão da parte do performer. Em acréscimo, os comentários do performer, que por vezes explicitam mais do momento da execução simplesmente por terem sido vivenciados, como condição humana, numa posição a posteriori, apontam para condições de respaldo e de anti-causalidades, pois são construídas a partir de retroalimentações do outro anteriormente, e nunca a título de justificar qualquer característica peculiar de força ou fraqueza. Como meio de ilustração, apresentaremos quadros com os relatos apreciativos dos pianistas solicitados, bem como a visão autocrítica do performer para cada performance da sexta peça da série $A$ Prole do Bebê no. 2: $O$ Boisinho de Chumbo. ${ }^{5}$

\section{Quadros de apreciação de $O$ Boisinho de Chumbo}

Avaliação do Recital 1

Quadro 1 - Avaliação de performance 1 de $O$ Boisinho de Chumbo

Fonte: Vieira, 2012.

\begin{tabular}{|c|c|c|c|c|}
\hline & Apreciador 1 & Apreciador 2 & Apreciador 3 & $\begin{array}{l}\text { Apreciacáo própria do } \\
\text { performer }\end{array}$ \\
\hline Andamentos & $\begin{array}{l}\text { Pouca conviçálo nas } \\
\text { mudancas de } \\
\text { andamento }\end{array}$ & $\begin{array}{l}\text { Bastante } \\
\text { cuidadoso. }\end{array}$ & & Os tempos sấo cstáveis. \\
\hline $\begin{array}{l}\text { Variacōes de } \\
\text { agógica }\end{array}$ & & Muito bom. & 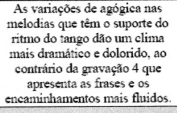 & 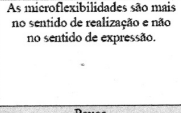 \\
\hline Acentuacào & & Ótimo. & & Pouca. \\
\hline $\begin{array}{l}\text { Dinâmica/ } \\
\text { Sonoridade }\end{array}$ & & Boa. & 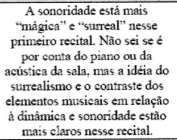 & Muito bom. \\
\hline $\begin{array}{l}\text { Valorizacàa de } \\
\text { dissonâncias }\end{array}$ & $\begin{array}{c}\text { Poderia } \\
\text { ter uma } \\
\text { melhor } \\
\text { polarizacâa } \\
\text { de acordes } \\
\text { mais ou } \\
\text { menos } \\
\text { dissonantes. } \\
\end{array}$ & Bom. & & $\begin{array}{l}\text { A preocupaç̆o maior } \dot{c} \mathrm{~cm} \\
\text { realizar a peça como um todo. }\end{array}$ \\
\hline Uso do pedal & $\begin{array}{l}\text { Uima } \\
\text { vez que } \\
\text { algumas } \\
\text { dissonanncias não } \\
\text { foram bem } \\
\text { valorizadas, opedal } \\
\text { acabou } \\
\text { ficando um } \\
\text { pouco sujo. } \\
\end{array}$ & $\begin{array}{l}\text { Ótimo, não } \\
\text { embarahlhou o } \\
\text { som! }\end{array}$ & & Estável. \\
\hline $\begin{array}{l}\text { Polinritmia } \\
\text { Énfase nos }\end{array}$ & & $\begin{array}{l}\text { Muito bom. } \\
\text { Analogia a um }\end{array}$ & & $\begin{array}{l}\text { Dibias. } \\
\text { Sugere um tango, mas ao longe. }\end{array}$ \\
\hline $\begin{array}{l}\begin{array}{l}\text { elementos } \\
\text { descritivos }\end{array} \\
\text { Clima }\end{array}$ & & $\begin{array}{l}\text { Gostei, muito } \\
\text { bom. }\end{array}$ & 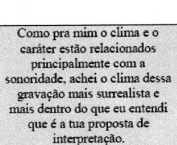 & Nebuloso. \\
\hline
\end{tabular}

${ }^{5}$ Os parâmetros utilizados para a construção desses quadros os mesmos presentes no trabalho sobre audição e análise de gravaçóes de outros pianistas da mesma suíte $A$ Prole do Bebê no. 2 realizado por Gorni (2008). 
Avaliação do Recital 2

Quadro 2 - Avaliação de performance 2 de $O$ Boisinho de Chumbo

Fonte: Vieira, 2012.

\begin{tabular}{|c|c|c|c|c|}
\hline & Apreciador 1 & Apreciador 2 & Apreciador 3 & $\begin{array}{l}\text { Apreciação própria } \\
\text { do performer }\end{array}$ \\
\hline Andamentos & $\begin{array}{l}\text { Melhor convicção nas } \\
\text { mudanças de } \\
\text { andamento. }\end{array}$ & Mais automatizado. & & $\begin{array}{l}\text { Os tempos começam a } \\
\text { adquirir uma } \\
\text { convicçăo de } \\
\text { concepcâo maior. }\end{array}$ \\
\hline Variaçöes de agógica & & $\begin{array}{l}\text { Bom-Mais } \\
\text { automatizado. }\end{array}$ & & $\begin{array}{c}\text { Caminhamm para a } \\
\text { possibilidade de } \\
\text { expressão de alguma } \\
\text { ideia extra-texto. Mas } \\
\text { ainda permeiamu o } \\
\text { ambito da realizaçăo. }\end{array}$ \\
\hline Acentuacào & & Otimo. & & Não o sufficiente. \\
\hline Dinämica/Sonoridade & & Boa. & & $\begin{array}{l}\text { A tendéncia é soar } \\
\text { tudo forte. }\end{array}$ \\
\hline $\begin{array}{l}\text { Valorizacāo de } \\
\text { dissonânucias }\end{array}$ & $\begin{array}{l}\text { Melhor do que no } \\
\text { recital 1, sobrendo na } \\
\text { primeira mudanç de } \\
\text { acordes. }\end{array}$ & Bom. & & $\begin{array}{l}\text { Alguma. A dinâmica } \\
\text { tende ao forte, entāo } \\
\text { as dissonâncias são } \\
\text { eclipsadas pela } \\
\text { massividade sonora. }\end{array}$ \\
\hline L'so do pedal & $\begin{array}{c}\text { Uma vez que as } \\
\text { dissonâncias foram } \\
\text { melhor ressaltadas, o } \\
\text { pedal ficou mais } \\
\text { elaro. }\end{array}$ & Ótimo. & & Bom. \\
\hline Polirritmia & & Bom. & & Regular \\
\hline $\begin{array}{l}\text { Ënfase nos elementos } \\
\text { descritivos }\end{array}$ & & Analogia a um tango. & & $\begin{array}{l}\text { O tango surge na } \\
\text { exposiçoo, mas ainda } \\
\text { falta conviçăao para } \\
\text { sustentar a ideia. }\end{array}$ \\
\hline Clima & & Bom. & & Pouco interessante. \\
\hline
\end{tabular}

Avaliação do Recital 3

Quadro 3 - Avaliação de performance 3 de O Boisinho de Chumbo

Fonte - Vieira, 2012.

\begin{tabular}{|c|c|c|c|c|}
\hline & Apreciador 1 & Apreciador 2 & Apreciador 3 & Apreciaçäo própria \\
\hline Andamentos & $\begin{array}{l}\text { Pulsos bem mais } \\
\text { fluidos, entâo as } \\
\text { mudanças de } \\
\text { andamento estăo } \\
\text { ainda methores. }\end{array}$ & Gostei - muito bom. & & $\begin{array}{l}\text { Ligeiramente mais } \\
\text { rapidos que nas } \\
\text { performance } \\
\text { anteriores. }\end{array}$ \\
\hline Variaçoes de agógica & $\begin{array}{l}\text { Melhor medida do que } \\
\text { nas outras } \\
\text { performances. }\end{array}$ & $\begin{array}{l}\text { Bom - Bem mais } \\
\text { desprendido. }\end{array}$ & $\begin{array}{l}\text { A condução de frases } \\
\text { eseçes sas } \\
\text { variaçes de agogogica } \\
\text { estâo mais fluentes. }\end{array}$ & $\begin{array}{l}\text { Acontecem de forma } \\
\text { orgânica visando a } \\
\text { expressividade. }\end{array}$ \\
\hline Acentuação & $\begin{array}{l}\text { Juntamente com } \\
\text { articulaçáa a } \\
\text { acentuacâo, foi } \\
\text { melhor realizada. }\end{array}$ & $\begin{array}{l}\text { Otimo-mais } \\
\text { decidido. }\end{array}$ & & $\begin{array}{c}\text { São, nessa } \\
\text { performance, } \\
\text { enfáticas. }\end{array}$ \\
\hline Dinânica/Sonoridacle & $\begin{array}{l}\text { Juntamente com a } \\
\text { acentraq̧ăo. }\end{array}$ & $\begin{array}{c}\text { Muito boa-Mais } \\
\text { assimulada. }\end{array}$ & & $\begin{array}{l}\text { A sonoridade tende a } \\
\text { ser muito bem } \\
\text { administrada. Porem, } \\
\text { tende ao forte. }\end{array}$ \\
\hline $\begin{array}{l}\text { Valorização de } \\
\text { dissonâncias }\end{array}$ & $\begin{array}{l}\text { Juntamente com } \\
\text { aspectos de } \\
\text { acentração melhores } \\
\text { realizados, a } \\
\text { valoriząăa das } \\
\text { dissonâncias foi } \\
\text { mellhor executada. }\end{array}$ & $\begin{array}{l}\text { Muito bom - mais } \\
\text { assimilada }\end{array}$ & & $\begin{array}{l}\text { Acontece com a } \\
\text { finalidade de ampliar } \\
\text { a gama sonora. A } \\
\text { paleta de som torma-se } \\
\text { mais ampla comn o } \\
\text { aproveitamento de } \\
\text { diversos spectros } \\
\text { atraiddos pelas } \\
\text { dissonâncias. }\end{array}$ \\
\hline Uso do pedal & Muito methor. & Ótimo. & & $\begin{array}{l}\text { Proficiente. } \\
\end{array}$ \\
\hline Polirvitmia & $\begin{array}{l}\text { Melhor das } 4 \\
\text { performances. }\end{array}$ & $\begin{array}{l}\text { Muito bom - mais } \\
\text { maduro. }\end{array}$ & & Bem realizadas. \\
\hline $\begin{array}{l}\text { Enfase nos elementos } \\
\text { descritivos }\end{array}$ & & $\begin{array}{l}\text { Analogia a um tango } \\
\text { mais assimilada. }\end{array}$ & & $\begin{array}{l}\text { A ideia de tango está } \\
\text { presente. }\end{array}$ \\
\hline Clima & $\begin{array}{l}\text { Achei a melhor } \\
\text { performance, pela } \\
\text { fluidez de } \\
\text { andamentos, clareza } \\
\text { de articulaçao e } \\
\text { pedalizaçąo mais } \\
\text { conscientes. }\end{array}$ & $\begin{array}{l}\text { Muito bom - mais } \\
\text { maduro. }\end{array}$ & & $\begin{array}{l}\text { Apesar de ser uma } \\
\text { performance "in } \\
\text { vitro", os aspectos de } \\
\text { clima e caráter são } \\
\text { bem expressados- } \\
\text { convincentes. }\end{array}$ \\
\hline
\end{tabular}


Avaliação do Recital 4

Quadro 4 - Avaliação de performance 4 de $O$ Boisinho de Chumbo

Fonte: Vieira, 2012.

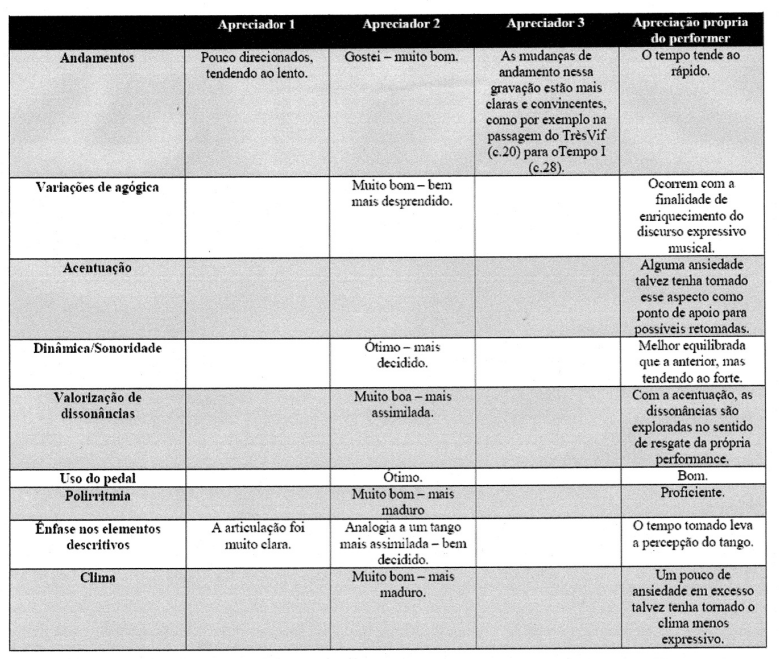

A observação das informações fornecidas por cada pianista apreciador denota como suas identidades individualmente revelam uma perspectiva de possibilidades multiplamente variadas, correspondendo a pluralidade de significações que o ato de performance musical, como ato interpretativo, pode representar. Por um lado pode levar a um panorama disperso, por outro atrai a percepção do êthos envolvido em sua condição humana, já que cada um é um diferente, e nesse sentido, a diferença convergindo para o próprio performer, a ideia de valer a apreciação como fonte de reflexão ainda permanece. Os apreciadores 1 e 3 não preencheram todos parâmetros solicitados. Por vezes, anotaram em um parâmetro específico algo que abarcava outros tópicos, concebendo sua apreciação de um modo a integrar a audição musical como um todo. Contudo, o mais considerável é que todos perceberam a depuração do trabalho ao longo do tempo. Nesse aspecto, inclusive, foi mencionado como um desses colaboradores informou pontos de vista em todos os parâmetros requeridos somente na performance 3 de $O$ Boisinho de Chumbo, que segundo nota dele, foi a melhor das quatro performances disponibilizadas. 
Outro aspecto, talvez mais tácito, mas muito importante no concernente à interpretação de uma obra, foi que os três apreciadores reconhecem a "formatividade das obras realizadas", ou seja, todos reconheceram que naquele momento registrado e posteriormente repassado a eles, A Prole do Bebê no. 2 de Villa-Lobos foi evocada e a peça $O$ Boisinho de Chumbo foi realizada como obra artística constituída. Essa implicação está carregada de força ontológica, impregnada de questões sobre autenticidades, porém, em se tratando da constituição artística do intérprete e sua constituição como sujeito de performance nessa peça de $A$ Prole do Bebê no. 2, já confia alguma validade ao aspecto metodológico denotado, pois um movimento de ascese foi percebido.

Qual o papel do feedback/feedforward do performer nesse contexto? Nesse sentido, o ato reflexivo o conduz à ponderação e à constituição a partir do olhar da alteridade. De fato, os informes apontados pelos outros pianistas, de maneira a iniciar um autoprocesso de subjetivação e constituição de si, o conduzem, naturalmente, à necessidade de uma outra performance, renovada, apropriada e em movimento de ascese de si para si. Preferimos retomar outros momentos do performer em sua constituição e a partir deles apontar alguma outra questão no sentido de crítica à performance.

\section{Da constituição de si}

A conjetura da performance como realidade de fato a priori, comentado no decorrer deste trabalho, valoriza aquilo que constitui a força de desvio e apropriação para a condição estética do vivenciado como condição de performance. O cuidado de si, nesse sentido, entendido como estética da existência, "diz respeito a um indivíduo livre, acompanhado de regras e valores" (Passetti, 2010), no caso, essas regras podem ser aquelas impostas pela tradição, mesmo que de sua própria autoria, porém os valores são atribuídos às condições dos próprios arquivos vinculados a si e do outro para si. O indivíduo livre estaria constituído, em si, no ato da performance, nos diferentes momentos resgatados? 
O valor atribuído a tal constituição não está ligado ao aperfeiçoamento real, mas ao jogo estabelecido na busca pela própria liberdade para se colocar a si como seu sujeito de conhecimento e de interpretação. Não obstante, a busca por essa liberdade é alcançada pelo cuidado de si em sua contínua descoberta.

Os arquivos aqui mencionados, entendidos como dispositivos do cuidado de si, apresentam os atos do conhecimento e a ideia de movimento ao voltar o olhar para si. Outra categoria de arquivos, contendo ideias, metáforas e imagens construídas como exercícios de reflexão - caracterizada como outra versão dos arquivos do performer - colaborou na conversão do exercício de consciência de si, ou seja, o próprio ato de subjetivação. O próprio movimento de olhar para si como conversão de si para si, a partir da subjetivação do cuidado em constituir-se com a valorização dos a priori, gera-se em função da consciência de si como ascese adquirida.

Nesse sentido, a subjetivação é muito distante de qualquer indicio ou prenúncio de subjetividade. Já que a utilização de arquivos como meio de resgate do êthos envolvido no aprimoramento de um ato de performance, e esse admitir um olhar de si convertido através do olhar do outro, o princípio da subjetivação torna-se forte ferramenta para a própria constituição do performer. Seus arquivos, ademais, contemplam excelente fonte de dados para a compreensão, mesmo de si próprio, e de seu processo como intérprete, além do amadurecimento como músico prático.

Em outra etapa, em parte como resultado do feedback/feedforward recebido e em resposta à constituição de si como ato aprimorado, e ainda como suporte para outras escolhas pianísticas e interpretativas, o performer realizou outra apresentação e gravação da obra mencionada. A gravação, então, foi submetida à apreciação de outros três pianistas, também, com titulação pósgraduada, sendo que o feedback/feedforward desses pianistas foi remetido por carta, tal qual na primeira etapa. Dessa vez, contudo, não foram estabelecidos parâmetros, apenas foi enviada a performance para os pianistas com uma carta explicando as ideias do performer.

Cada uma das apreciações mostrou-se particular. Cada pianista destacou algum aspecto diferente, de maneira que os seus comentários foram genéricos, 
mas constituíram um todo. Inserimos trechos das cartas recebidas pelo performer com o objetivo de mostrar como aquelas palavras podem, agora, tornar-se algo da essência do músico em sua atividade, em sua própria medida.

Primeira apreciação (correspondência recebida em 31 de março de 2012):

Caro [...], antes de mais nada, gostaria de lhe dar os PARABÉnS pelo seu trabalho! As execuções estão em altíssimo nível, e agradeço também pelo convite em participar dessa experiência.

Parabéns! Você domina muito bem as obras. Como você escreveu, a primeira apresentação pública foi em 2008, não é? A sua performance transparece este tempo de amadurecimento. Transparece segurança e domínio.

$[\ldots]$

O Boizinho de chumbo - A sua leitura rítmica é bastante precisa, o que empresta estabilidade ao ostinato, e amarra a sua performance. Bárbaro. No entanto, acredito que os cantos/contracantos marcados por acentos poderiam se beneficiar de uma malemolência e talvez eu possa dizer liberdade ainda maior. Penso que fica interessante, pois contrasta com o ostinato rítmico. Veja bem, aqui também já estamos no terreno do gosto pessoal. Penso que o fascinante no nosso trabalho é isto. Cada intérprete terá a sua concepção pessoal da obra, o que torna cada escuta uma nova experiência.

Pontuando alguns detalhes: todas as figurações de pequenas escalas cromáticas poderiam se beneficiar por um crescendo mais explícito, e em legatíssimo. Essa observação contribui também para o "malemolente" que comentei acima. Especialmente no final da obra, quando essa figuração ganha destaque, é importante que a condução ocorra de forma ainda mais explícita, ainda que a dinâmica esteja em $p p$, e ppp.

A seção do Trés vif, que antecede a retomada do tempo I, de certa forma está um pouco destacada do restante da performance. Está resolvida tecnicamente, mas acho que a costura do trecho na obra pode ser melhor.

Reitero novamente os meus parabéns pelo seu trabalho!

Um abraço (Destaques do apreciador).

A apreciação salienta o domínio da obra e valoriza aspectos relacionados à precisão rítmica que a performance lhe comunicou. Suas sugestões com relação à flexibilização agógica ressaltam a consciência do gosto pessoal. A sua fala "Cada intérprete terá a sua concepção pessoal da obra, o que torna cada escuta uma nova experiência" denota o valor das escolhas diferentes de cada intérprete em cada momento, diretamente ligado à concepção estética que foi admitida para a construção e constituição dessa performance.

Segunda apreciação (correspondência recebida em 26 de março de 2012): 
Boizinho de Chumbo

"Boizinho de chumbo" é uma peça que exige do intérprete grande virtuosismo técnico, substancioso volume sonoro, e equilíbrio entre articulação rítmica e canto expressivo. Nesta interpretação esta atmosfera global é delineada com coerência, maturidade e especialmente valorizada por sua riqueza de efeitos tímbricos. Os agrupamentos de frases são encadeados com virtuosismo técnico e recursos de expressão que valorizam a conexão dos eventos. Após uma introdução bem ritmada e articulada, surge uma cantilena saudosa e triste que se caracteriza pelas surpresas do fluxo de dinâmica e de timing gerenciados pelo intérprete. Na seção $B$, de intenção mais virtuosística, a ideia de fluxo improvisado de eventos parece se consolidar. A volta da cantilena é retomada inicialmente com a mesma riqueza sonora. Entretanto, o canto aqui parece estar ofuscado, ou quase diluído pelos ornamento/glissandi (intenção deliberada do interprete?). Na seção Lent retomada do caráter expressivo e saudoso. No Grandioso, a performance é concluída valorizando o volume sonoro inicial, bem como o controle no decrescendo que finaliza a peça em $p p p$.

$[\ldots]$.

Esta apreciação estabelece parâmetros de escuta: atmosfera global, efeitos tímbricos, agrupamentos de frases, fluxo de dinâmica e timing. Nessa delimitação transpareceu a busca por uma idoneidade do apreciador. Todavia, por algum momento lembra que questões de interpretação musical, em qualquer âmbito, envolvem decisões deliberadas do executante. Os seus comentários, de todo modo, foram muito específicos e tendiam a ouvir concepções 'prontas', isto é, algo previamente aguardado pelo ouvinte.

Terceira apreciação (correspondência do dia 26 de março de 2012):

O boisinho de chumbo

A partir das tuas reflexões sobre a questão do surrealismo nessas peças de Villa-Lobos, eu já ouvi o boisinho de chumbo pensando na questão da realidade versus sonho. Então pra mim o baixo das colcheias em stacatto me parece a dose de realidade da peça toda, juntamente com a articulação seca e precisa da mão direita. Então quando entra o $4^{\circ}$ compasso, me parece a ilusão de uma melodia com a condução cromática da linha superior começando com um acorde arpejado.

[Insere um exemplo musical dos compassos 5 e 6 de 0 boisinho de chumbo].

A voz interna, que antes fazia parte da característica rítmica da "realidade", agora se torna um plano de fundo no mundo dos sonhos, voltando a representar a realidade no compasso 9 pela ausência do pedal de sustentação e pela mesma articulação dos compassos iniciais. Talvez você pudesse deixar essa voz mais longe, mais etérea pra contrastar com o compasso que ela aparece seca, sozinha. 
[Insere um exemplo musical do compasso 9 d'O Boisinho].

Quando o baixo em colcheias surge novamente, segue-se logo após um devaneio no movimento ascendente do compasso 11 e no seu seguimento.

[Exemplo do compasso 13-14 do Boisinho].

No momento Très Vif (compasso 22), o movimento descendente me faz pensar sobre a saída do patamar superior que seria o mundo onírico para uma volta à realidade, culminando na volta do baixo rinforzando que caminha para o lá do baixo inicial (Tempo I), como um aviso de "acorda" do mundo onírico do compasso 13 ao 21.

[Exemplo c. 20-30 de O boisinho de chumbo].

A melodia da voz interna (chanté) traz o elemento da ilusão de volta com a condução cromática e com as apoggiaturas também cromáticas.

[Figura com os cc. 34-36 de O boisinho...]

Na seção Lent, a partir do compasso 50, tua ideia me dá uma noção de interrupção da realidade, uma percepção de que o sonho não passa de um sonho, havendo um conflito entre sonho e realidade no momento que entra a voz interna cromática bien chanté e segue animando pouco a pouco.

[Exemplo musical com os cc. 50-59 de O boisinho de chumbo].

Esses comentários parecem procurar envolver algo das ideias que foram escritas na carta de apresentação da performance. O apreciador tende a buscar aspectos que comunicaram ou deixaram a desejar em sua percepção das ideias do performer. Essa maneira de articular a sua apreciação pareceu muito pertinente com o aspecto de se envolver e participar da constituição do intérprete. O pianista inseriu exemplos musicais para cada passagem que gostaria de destacar, talvez para deixar o seu comentário mais nítido e mostrar, como aquilo, seria importante para ser repensado pelo performer.

Retomando algumas considerações já mencionadas com relação aos comentários do segundo apreciador, ampliamos o seu sentido e significado para todo o exercício de apreciação que foi construído e considerado nessa etapa e mesmo na anterior. Se a fala do outro tende a ser normativa, então continua em sua validade conferindo formatividade na concepção musical do intérprete e em sua constituição, além de inspirar apropriação a ser retomada em um momento futuro.

Nesse sentido, uma possível apreciação específica, pelo próprio performer elaborada, agregaria tal valor. Solicitamos ao performer que construísse um quadro de avaliação da performance dessa última etapa a partir dos parâmetros considerados nas performances anteriores. Destacamos a imanente condição 
convertida por essa tarefa como constituição de mais um a priori para a sua atividade como performer dessa obra, como ilustra o Quadro de Avaliação após apreciação da alteridade:

Quadro de avaliação após a alteridade

Quadro 5 - Avaliação após apreciação da alteridade.

Fonte: Vieira, 2012

\begin{tabular}{|c|c|}
\hline & O Boisinho de chumbo \\
\hline Andamentos & Moderados. \\
\hline Variações de Agógica & $\begin{array}{l}\text { Bastante flexivel. Cada passagem de uma seção } \\
\text { para a outra foi bem pensada. }\end{array}$ \\
\hline Acentuação & $\begin{array}{l}\text { Os acentos são realizados em funç̧ão de destacar } \\
\text { alguns elementos estruturais. Em geral, a } \\
\text { articulação informada na partitura é objetivada. }\end{array}$ \\
\hline Dinâmica & Boa dimensăo de sonoridade. \\
\hline Valorizaçào das dissonâncias & $\begin{array}{l}\text { As dissonâncias tendem a estar inseridas no } \\
\text { âmbito de dinâmica/sonoridade, criando um } \\
\text { vasto colorido. }\end{array}$ \\
\hline Uso do Pedal & $\begin{array}{l}\text { O pedal é usado parcamente, podendo ser mais } \\
\text { abundante. O uso do pedal tonal colaborou para } \\
\text { a projecão de um discurso mais seco. }\end{array}$ \\
\hline Polirritmias & $\begin{array}{l}\text { Nesta performance um grau minimo de exatidâo } \\
\text { foi atingido. }\end{array}$ \\
\hline Êufase nos elementos descritivos & O espírito de tango desvairado está presente. \\
\hline Clima & $\begin{array}{l}\text { A sonoridade e os tempo tomados e articulações } \\
\text { são, em geral, bem delineados, transcendendo } \\
\text { aspectos puramente técnicos. Assim, o } \\
\text { clima/caráter da peça é construido a partir das } \\
\text { imagens: creio que a intençào do tango } \\
\text { surrealista possa ser percebida. }\end{array}$ \\
\hline
\end{tabular}

Esse quadro de apreciação converte-se do performer para sua própria constituição. Principalmente por ter sido elaborado após o recebimento das cartas de apreciação dessa segunda etapa. Tal constituição denota a ideia de apropriação das construções e elaborações sobre o discurso musical da alteridade como suas, de maneira que a performance realizada se torna obra de sua própria autoria, em coautoria com o compositor. Desse modo, a performance não nega o caráter villalobiano natural, mas se instrui com o conhecimento do texto musical e de reflexão do próprio intérprete a partir de seu próprio ato de aprimoramento, quer empírico-performático como filosófico de atitude estética pretendida.

É certo que um movimento de apropriação acontece quando nos tornarmos coautores da obra no momento da performance. Ao ouvir nossa própria performance e ao tecer comentários de apreciação que tal ato se converte de si para si e ainda, ao afirmar que as palavras de apreciadores externos tornamse parte de sua própria essência, a concepção passa a ser associada ao reencontro do ato humano com o ato exterior, ao converter-se como de origem própria: sua 
constituição é atingida através desse processo de reflexão musical - autorreflexão - e principalmente de interação reflexiva. Citamos, com isso, as palavras de Jacques Derrida em que a arte pode ser oriunda de uma determinação filosófica e vertendo seu pensamento da filosofia para a música, pode determinar fundamento para a arte da performance musical: "Pois a filosofia foi determinada na sua história como reflexão da inauguração poética" (Derrida, 2009, p. 38).

\section{A título de conclusão}

A metodologia - construção, valorização e utilização de arquivos de performance para memória do próprio performer - foi desenvolvida tendo em vista a construção de uma crítica sistemática de reflexão epistemológica: a partir do ato admitido como pressuposto metodológico (a constituição de si) e a colaboração do performer como sujeito deste trabalho na busca por sua própria constituição. Admitir tal problemática de pesquisa não foi simples e condicionou o aspecto metodológico a uma ruptura de paradigma que visou à produção de conhecimento em confronto com o senso comum, e também a sua formação a partir de uma atividade reflexiva e original. Tal colocação desidealiza as sugestões de Barrenechea (2003) e Aquino (2003) que discursaram e indicaram a interrelação entre o trabalho de pesquisa e a práxis profissional do pesquisador brasileiro na área das práticas interpretativas.

Os constructos originários por meio deste trabalho valeram-se de uma atividade empírica, realizada e registrada a título de amostra, mas não de caráter experimental. A intenção sempre fora o aprimoramento da realização musical e consequentemente uma maior efetividade do músico como instrumentista e indivíduo de realização estética. O cuidado de si, que prevê o relacionamento e a valorização da ação do outro para a constituição do eu ali presente, verteu-se em ferramenta metodológica de maneira a levar à formação de arquivos de natureza revisionária e funcionou como instrumento de memórias para uma posterior reflexão e apropriação. 
A manutenção de um arquivo de atividades de natureza apriorística começa a vincular o ato empírico da performance ao ato de cuidado de si. Voltar à própria atividade após tê-la realizado, mostrou-se como excelente meio de reflexão sobre o próprio fazer estético, a ponto de inicialmente tornar-se elemento de questionamento sobre a natureza desse próprio fazer. O registro da prática constituiu uma memória material e compôs um material acumulado para releitura e meditação posterior. Formou a matéria prima para a articulação e conformação de próprias ideias musicais do performer envolvido, como instrumentos de reflexão filosófica, quer para a pesquisa como para a música. Serviu, ainda, como material de enquadre para supostas atividades de autorregulação: refinamento de audição, meditação e conversa consigo mesmo. A manutenção desses registros colaborou com o processo de apropriação.

O movimento de subjetivação, a fim de constituir-se a si, completa-se, nesse sentido, como um círculo hermenêutico de convergência. Tal convergência age uma hermenêutica de si para si, por parte do interprete envolvido, já que os significados de todas as ações se convertem a ele, a partir e sempre do seu olhar sobre o outro para consigo.

A ação sobre o olhar do outro para ver a si é, em parte, a característica descontínua do processo de performance. No entanto, é o meio de atingir o estado de conhecimento de si. A ação descontínua em movimento de ascese é a principal característica do desejo de aprimoramento e a conversão de si sobre si mesmo atua como predicação da estética da existência.

Nesse sentido, a estética da existência, as práticas de si e o cuidado de si, conduzem à catarse e incrementam a constituição individual, mesmo em uma atitude de natureza estética-performática, no caso da música. Descobre-se a um só tempo sobre si na contemplação de suas verdades permitindo fundar-se a si em sua vivificação real. Isso conduz ao desprendimento gradual do si em direção à alteridade, sem que essa ação se constitua no final indicador de sua própria valorização. A meta do cuidado de si é o seu reconhecimento e esta assume uma dimensão diante da vida. Constituir-se como sujeito estético a partir de um ato estético, como o proposto como processo para o performer aqui tomado como sujeito, é tarefa de uma vida condicionada à sua própria subjetivação. A 
compreensão de si e seu autoconhecimento são formas de se conseguir um aprimoramento, mesmo numa situação artística e de performance musical. As práticas de si permitem encontrar ferramentas a fim de atingir esse estado de ascese.

As atividades propostas como manutenção de arquivos do próprio perfomer e de suas performances constituíram apenas exemplos, contudo, essenciais para o processo de aperfeiçoamento estético e de constituição individual a ele próprio. A preocupação central das atividades foi inseri-lo e incluí-lo dentro de uma tradição artística. Se os dispositivos escolhidos foram assertivos, valem como sugestão de que o processo de performance vinculado ao processo do cuidado de si e 'o movimento de olhar para si' conformam uma etapa de reflexão para a constituição do individuo artístico. Porém, a ideia de que cada um conhece ou deve conhecer a sua própria medida completará as diversas possibilidades de sugestão, visto que essas atividades visam apenas à constituição, cuidado e subjetivação de sujeitos caracterizados individualmente.

\section{Referências}

ABBAGNANO, Nicola. Dicionário de Filosofia. $2^{a}$ ed. São Paulo: Martins Fontes, 1998.

AQUINO, Felipe A. Práticas Interpretativas e a Pesquisa em Música: dilemas e propostas. Opus 9 - Revista da Associação Nacional de Pesquisa e Pós-Graduação em Música / ANPPOM. Dezembro - 2003. Disponível em: http://www.anppom.com.br/opus/opus9/opus9-8.pdf. Acesso em 03/03/2011.

BARRENECHEA, Lúcia. Pesquisa no Brasil: Balanço e Perspectivas. Opus 9 - Revista da Associação Nacional de Pesquisa e Pós-Graduação em Música / ANPPOM. Dezembro - 2003. Disponível em: http://www.anppom.com.br/opus/opus9/opus9-9.pdf. Acesso em 03/03/2011.

CASTRO, Edgardo. Vocabulário de Foucault: um percurso pelos seus temas, conceitos e autores. Belo Horizonte: Autentica Editora, 2009.

DANIEL, Ryan. Self-assessment in performance. British Journal of Music Education. V. 18, no. 3, Cambridge, p. 215-226, 2001.

FOUCAULT, Michel. A Hermenêutica do Sujeito: Curso dado no Collège de France (1981-1982). Tradução: Márcio Alves da Fonseca, Salma Tannus Muchail. $3^{a}$ edição. São Paulo: WMF Martins Fontes, 2010. 
GORNI, Carla. A Prole do Bêbe $n^{\circ} 2$ de Villa-Lobos: Contribuições da análise e do imaginário musical para sua interpretação - um estudo de cinco gravações. UNIRIO. Rio de Janeiro. 2007. Dissertação de Mestrado.

MOLINA (Jr). Sidney José. O violão na era do disco: interpretação e desleitura na arte de Julian Bream. PUC-SP. São Paulo. 2006. Tese Doutorado.

PAREYSON, Luigi. Os Problemas da Estética. São Paulo: Martins Fontes, 1997.

PASSETTI, Edson. Acompanhar Foucault: Por que sim, e expor minhas inquietações, Por que não? RAGO, Margareth (Org). Foucault e as estéticas da existência. Disponível

http://www.unicamp.br/ aulas/flowplayer/example/passeti.html.

em: 30/07/2011.

PHILIP, Robert. Performing Music in the age of recording. New Haven \& London: Yale University Press, 2004.

SANTOS, Boaventura de S. Introdução a uma Ciência Pós-Moderna. 6a Edição. Porto: Afrontamento, 2002.

VIEIRA, Daniel. 'Boisinhos' e 'Lobosinhos' de Heitor Villa-Lobos: O cuidado de si no processo de performance como crítica para a constituição de um sujeito de atitude estética. UFRGS. Porto Alegre. 2012. Tese de Doutorado. 